\title{
Historic Stroke Motor Severity Score Predicts Progression in TIA/Minor Stroke
}

\author{
Marie-Christine Camden, Michael D. Hill, Andrew M. Demchuk, \\ Alexandre Y. Poppe, Nan Shobha, Philip A. Barber, Shelagh B. Coutts
}

\begin{abstract}
Background: Transient ischemic attack (TIA) and minor stroke have a high risk of early neurological deterioration, and patients who experience early improvement are at risk of deterioration. We generated a score for quantifying the worst reported motor and speech deficits and assessed whether this predicted outcome. Methods: 510 TIA or minor stroke (NIHSS $<4)$ patients were included. The Historical Stroke Severity Score (HSSS) prospectively quantified the patient's description of the worst motor or speech deficits. The HSSS was rated at the time of first assessment with more severe deficits scoring higher. Motor HSSS included assessments of arm and leg motor power (score total 0-5). Speech HSSS assessed severity of dysarthria and aphasia (total 0-3). The association between motor and speech HSSS and symptom progression was assessed during the 90-day follow-up period. Results: The proportion of patients in each category of the motor HSSS was 0: 43\% (216/510), 1: 22\%(110/510), 2: 17\% (89/510), 3: 7\% (37/510), 4: 5\% (28/510) and 5: 6\% (30/510). Motor HSSS was associated with symptom progression $(\mathrm{p}=0.004)$ but not recurrent stroke. Speech HSSS was not associated with either progression or recurrent stroke. Motor HSSS predicted disability $(\mathrm{p}=0.002)$ and intracranial occlusion $(\mathrm{p}=0.012)$. Disability increased with increasing motor HSSS. Conclusions: Taking a detailed history about the severity of motor deficits, but not speech, predicted outcome in TIA and minor stroke patients. A score based on the patient's description of the severity of motor symptoms predicted symptom progression, intracranial occlusion and functional outcome, but not recurrent stroke in a TIA and minor stroke population.
\end{abstract}

RÉSUMÉ: Le Historical Stroke Severity Score moteur prédit la progression d'un accès ischémique cérébral transitoire / d'un accident vasculaire cérébral mineur. Contexte : L'accès ischémique cérébral transitoire (ICT) et l'accident vasculaire cérébral mineur (AVCM) comportent un risque élevé de détérioration neurologique précoce et les patients chez qui on observe une amélioration précoce sont à risque de détérioration. Nous avons élaboré un score pour quantifier les pires déficits moteurs et du langage rapportés et nous avons évalué si ceci prédisait l'issue. Méthode : Cinq cent dix patients atteints d'une ICT ou d'un AVCM (NIHSS < 4) ont été inclus dans l'étude. Le Historical Stroke Severity Score (HSSS) a servi à quantifier prospectivement la description du pire déficit moteur ou du langage que le patient avait présenté. Le HSSS a été évalué au moment du premier examen que le patient a subi, les déficits plus sévères recevant un score plus élevé. L'évaluation motrice du HSSS incluait des évaluations de la force motrice des bras et des jambes (score total 0 à 5). Le HSSS évaluait la sévérité de la dysarthrie et de l'aphasie (total 0 à 3 ). L'association entre le score moteur et celui du langage au HSSS et la progression des symptômes ont été évaluées au cours de la période de suivi de 90 jours. Résultats : La proportion de patients dans chaque catégorie du HSSS moteur était $0: 43 \%$ (216/510), $1: 22 \%$ (110/510), $2: 17 \%$ (89/510), $3: 7 \%$ (37/510), $4: 5 \%$ $(28 / 510)$ et $5: 6 \%(30 / 510)$. Le score HSSS moteur était associé à la progression des symptômes $(\mathrm{p}=0,004)$ mais il n'était pas associé à un deuxième AVC. Le HSSS du langage n'était pas associé à la progression ou à un deuxième AVC. Le HSSS moteur prédisait l'invalidité $(\mathrm{p}=0,002)$ et l'occlusion intracrânienne ( $\mathrm{p}=0,012)$. L'invalidité augmentait avec l'augmentation du HSSS moteur. Conclusions : Une histoire détaillée sur la sévérité des déficits moteurs prédisait l'issue chez les patients présentant une ICT ou un AVC mineur, ce qui n'était pas le cas pour les déficits du langage. Un score fondé sur la description faite par le patient de la sévérité des symptômes moteurs prédisait la progression des symptômes, l'occlusion intracrânienne et l'issue fonctionnelle, mais non un AVC subséquent chez des patients présentant une ICT ou un AVCM.

Can J Neurol Sci. 2014; 41: 19-23

Technological evaluation of stroke patients with imaging and other diagnostic tests have greatly enhanced our understanding of the disease and directed management, perhaps at the expense of de-emphasizing the traditional clinical skills of careful medical history taking and physical examination. The patient with transient ischemic attack (TIA) or minor stroke is by definition mildly affected enough that a careful history of the stroke event can be taken directly from the patient.

Previous studies to identify patients who are at high risk for recurrent stroke after TIA have looked at features of the patient (e.g. diabetes mellitus ${ }^{1}$ and hypertension ${ }^{1}$ ) and the event (symptom duration $>10$ minutes, weakness or speech disturbance $^{2}$ ) to predict the risk of recurrent stroke. Using a combination of many of these factors, clinical stratification tools (California ${ }^{1}, \mathrm{ABCD}^{2}$ and $\mathrm{ABCD} 2^{3}$ scores) have been developed to help identify patients at high risk of recurrent events, with the

From the Departments of Clinical Neurosciences (MCC, MDH, AMD, AYP, NS, PAB, SBC), Radiology (MDH, AMD, PAB, SBC), Community Health Sciences and Medicine (MDH), Hotchkiss Brain Institute (MDH, AMD, PAB, SBC), University of Calgary; Notre-Dame Hospital, Centre hospitalier de l'Université de Montréal (AYP); Département des Sciences Neurologiques (MCC), CHU (Enfant-Jésus), Laval University, Quebec City, Quebec, Canada; Bangalore Neuro Centre (NS), Bangalore, India.

Received May 28, 2013. Final Revisions Submitted July 22, 2013. Correspondence to: Shelagh B. Coutts, Foothills Hospital, C1261, 1403 29th St NW, Calgary, Alberta, T2N 2T9, Canada. Email: scoutts@ucalgary.ca. 
aim of urgent hospitalization and investigation. These scores have shown mixed usefulness in the triage of patients with TIA ${ }^{4}$ and the recently updated Canadian secondary Stroke prevention guidelines ${ }^{5}$ do not recommend use of the $\mathrm{ABCD}^{2}$ score.

Previous work has shown that patients with large early neurological improvement are at high risk of subsequent deterioration. ${ }^{6,7}$ Many of these early recurrent events are due to stroke progression attributable to the evolution of the ischemic core into the surrounding penumbral tissues and others are likely due to re-embolization. ${ }^{8,9}$ As motor and speech symptoms are the most important in terms of prediction of recurrence ${ }^{3}$ we identified these as important symptoms to assess in a detailed manner. Previous work has simply rated the presence or absence of motor or speech symptoms and made no attempt to rate their severity. Clinical experience frequently makes us more concerned about a patient who describes transient hemiplegia than one who describes some mild "heaviness" of the arm.

We therefore hypothesised that patients with TIA or minor stroke who have historically more clinically severe deficits are at high risk of worsening due to symptom progression. We prospectively rated the self-reported worst historical deficit and used this new score to attempt to predict symptom progression, intracranial occlusion, recurrent stroke and disability in a population of minor stroke and TIA patients. We also hypothesised that the severity of the worst deficit would predict symptom progression rather than a distinct recurrent stroke.

\section{Methods}

\section{Patients}

Consecutive patients aged at least 18 years presenting with a high risk TIA (focal weakness or speech disturbance lasting $\geq$ five minutes) or a minor ischemic stroke (National Institute of Health Stroke Scale (NIHSS) score $\leq 3$ ) who were referred to Foothills Medical Center (a tertiary referral centre) were prospectively considered for enrolment in the CATCH study ${ }^{10}$ between April 2009 and September 2011. Patients with isolated sensory symptoms or isolated vertigo were specifically not eligible for CATCH. Details have been previously published. Briefly, patients were examined by a stroke neurologist and had a computed tomogram (CT) brain and CTA (aortic arch to vertex) completed within 24 hours of symptom onset. Exclusion criteria included: pre-morbid modified Rankin scale (mRS) 2 or greater, acute treatment with a thrombolytic drug, or a serious co-morbid illness that would likely result in death within three months. The local institutional ethics committee approved this protocol and patients provided written informed consent. Detailed baseline clinical and outcome information was prospectively collected for each patient.

\section{Historical Stroke Severity Score}

The Historical Stroke Severity Score (HSSS) was developed prior to the start of the CATCH study to allow measurement of the severity of the patient's description of the maximum motor and speech deficits that they had experienced.

The historic stroke motor severity score was scored based upon the clinical history taken from the patient at the first point of assessment by the stroke neurology team. This was always within 24 hours of symptom onset and was not repeated. The score rated the severity of the motor deficit in the affected arm and leg separately:

a. Arm motor power (score): normal (0), mild weakness or heaviness (1), moderate weakness (2), severe weakness (3),

b. Leg motor power (score): normal (0), mild weakness or heaviness (1), moderate weakness (2), severe weakness (3).

Each category was defined by the patient's description of their symptoms. If the patient used the word "mild" or heavy to describe the weakness, this was given a score of 1 for the affected limb. Severe weakness was defined as complete loss of function of the arm or the leg (plegia), no matter the duration of the symptom. Everything in-between mild and severe weakness was defined as moderate weakness. Arm and leg motor power scores were then combined to give a total score out of 6 . For example, if a patient was at some point unable to move his right arm and the worst motor deficit in his right leg was heaviness, his total score was 3 (arm motor power) +1 (leg motor power) $=$ 4. Given the low number of patients in groups 5 and 6 (most severe deficits) these scores were collapsed into one group to give a total score ranging from 0 to 5 . See Table 1 for details.

The historic stroke speech severity score was also based upon the clinical history taken from the patient at the time of first assessment and ranged from 0 to 3 points: normal (0), dysarthria or mild aphasia (1), moderate aphasia (2), severe (global) aphasia (3). Aphasia was based on the description of the patient with regards to the worst speech deficit. Mild word finding difficulty or dysarthria was scored as 1 . Severe aphasia with involvement of both comprehension and fluency with great difficulty in communicating was scored as 3 , with moderate aphasia being in -between these two categories.

\section{Outcomes}

Patients were assessed separately for the evidence of symptom progression or a distinct recurrent stroke during the 90day follow-up period. Patients were carefully followed clinically

Table 1: Historic stroke motor severity score

\begin{tabular}{l|l|l}
\hline \multicolumn{2}{l|}{ Description of maximum historical motor deficit. } & Score \\
\hline Arm Motor Power: & Normal & 0 \\
\hline & Mild weakness or heaviness & 1 \\
\hline & Moderate weakness & 2 \\
\hline & Severe weakness: plegia & 3 \\
\hline Leg motor power & Normal & 0 \\
\hline & Mild weakness or heaviness & 1 \\
\hline & Moderate weakness & 2 \\
\hline & Severe weakness: plegia & 3 \\
\hline
\end{tabular}

Scores for arm and leg are then combined giving a score ranging from 0-6. Due to small numbers total scores of 5 and 6 were then combined to give a total score ranging from $0-5$. 
Table 2: Number and percentage of patients with symptom progression, recurrent stroke, intracranial occlusion and disability $(\mathrm{mRS} \geq 2)$ according to the motor HSSS

\begin{tabular}{l|l|l|l|l|l|l|r}
\hline \multirow{2}{*}{ Outcome } & \multicolumn{5}{c}{ Motor HSSS \% (n/N) } & \multicolumn{1}{c}{} \\
\cline { 2 - 8 } & $\mathbf{0}$ & $\mathbf{1}$ & $\mathbf{2}$ & $\mathbf{3}$ & $\mathbf{4}$ & $\mathbf{5}$ & p value* \\
\hline Progression of symptoms & $1.4(3 / 213)$ & $3.7(4 / 108)$ & $5.9(5 / 85)$ & $5.4(2 / 37)$ & $7.1(2 / 28)$ & $10.7(3 / 28)$ & 0.004 \\
\hline Recurrent stroke & $2.8(6 / 213)$ & $2.8(3 / 108)$ & $5.9(5 / 85)$ & $5.4(2 / 37)$ & $3.6(1 / 28)$ & $3.6(1 / 28)$ & 0.432 \\
\hline Intracranial occlusion & $9.7(21 / 216)$ & $5.5(6 / 110)$ & $9(8 / 89)$ & $10.8(4 / 37)$ & $21.4(6 / 28)$ & $23(7 / 30)$ & 0.012 \\
\hline Disability (mRS $\geq 2)$ & $12(26 / 213)$ & $12(13 / 108)$ & $16.5(14 / 85)$ & $13.5(5 / 37)$ & $17.9(5 / 28)$ & $39.3(11 / 28)$ & 0.002 \\
\hline
\end{tabular}

510 patients were enrolled, 499 had follow up assessment available. *P value refers to a $\chi^{2}$ test for trend across ordered groups

and examined by a neurologist for evidence of symptom progression. Most patients were admitted to hospital. Patients were routinely followed-up at 90 days. At this time the modified Rankin Score (mRS) was assessed. Patterns of new lesions or infarct growth on follow-up imaging were used together with the clinical information to rate each event as either symptom progression or recurrence. ${ }^{8}$ Symptom progression was defined as a worsening of the presenting symptom related to the initial event. Recurrent stroke was defined as a new sudden focal neurological deficit of vascular origin lasting at least 24 hours that was distinct from the presenting event. Disability was defined as $m R S \geq 2$ at 90 days. The CTA was assessed by a single radiologist for the presence of an intracranial occlusion.

\section{Statistical analysis}

Statistical analysis was completed using Stata (Version 12). Primary outcome was symptom progression or recurrent stroke within 90 days. The motor and speech HSSS's were both assessed for prediction of the primary outcome. If the score was associated with the primary outcome then the secondary outcomes were assessed. Secondary outcomes included intracranial vessel occlusion on CTA and disability on the mRS at 90 days $(\mathrm{mRS} \geq 2)$. A chi-squared test for trend was used to assess the association between the ordered groups defined by the HSS score and the primary and secondary outcomes.

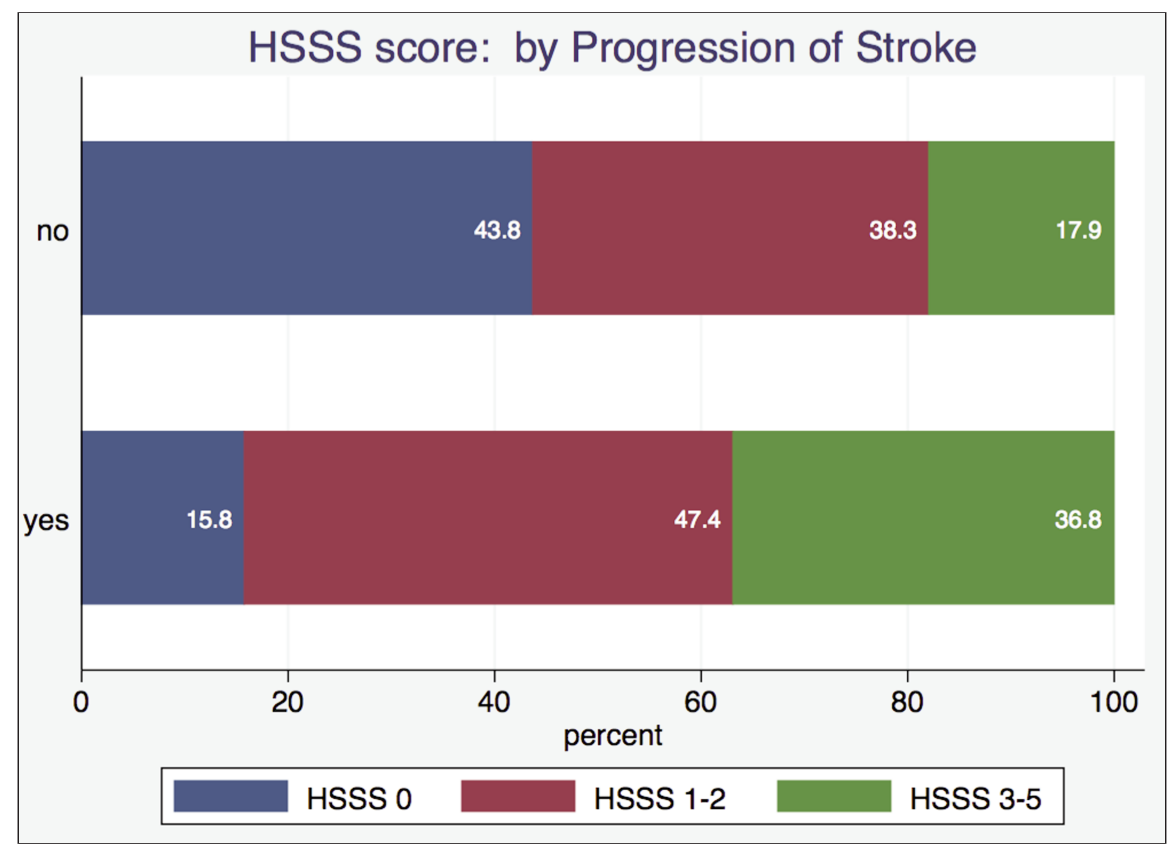

Figure: Bar graph showing proportion of patients in the different categories of HSS stratified by stroke progression or not. 


\section{RESULTS}

Five hundred and ten patients were enrolled. Follow-up information was available on $98 \%$ (499/510). Sixty-nine percent $(354 / 510)$ were $\geq 60$ years old, $59 \%(302 / 510)$ were male, $15 \%$ (77/510) had diabetes mellitus and 56\% (285/510) had hypertension. Sixty-one percent (313/510) patients had ongoing symptoms at the time of first assessment. The median NIHSS was 1 (interquartile range (IQR): 2). Eleven patients (2.2\%) were lost to follow-up and five patients (1\%) died during the 90-day follow-up period. There were $36(7.1 \%)$ recurrent events including 19 with symptom progression and 17 recurrent strokes. The proportion of patients in each category of the motor HSSS was $43 \%(216 / 510)$ with a score of $0,22 \%(110 / 510)$ with a score of $1,17 \%(89 / 510)$ with a score of $2,7 \%(37 / 510)$ with a score of $3,5 \%(28 / 510)$ with a score of 4 and $6 \%$ (30/510) with a score of 5 . The proportion of patients in each category of the speech HSSS was $37 \%(187 / 510)$ with a score of $0,36 \%$ $(185 / 510)$ with a score of $1,19 \%(99 / 510)$ with a score of 2 and $8 \%(39 / 510)$ with a score of 3.

Higher motor HSSS (indicating greater initial severity of deficits) was associated with symptom progression $(\mathrm{p}=0.004$, see Table 2 and Figure), intracranial occlusion $(p=0.012)$ and disability $(\mathrm{p}=0.002)$. Increasing motor HSSS was not associated with recurrent stroke $(\mathrm{p}=0.432)$. Speech HSSS was not associated with symptom progression $(\mathrm{p}=0.188)$ or recurrent stroke $(\mathrm{p}=0.062)$.

\section{Discussion}

We found that a simple score describing the patient's historical assessment of the severity of the worst motor deficits involving the arm and the leg was associated with symptom progression, intracranial occlusion and disability in TIA and minor stroke patients. A careful and detailed history of the stroke event is highly meaningful in identifying higher risk patients. We did not find that a score assessing speech severity was helpful.

Previous reports from the TOAST trial ${ }^{6}$, the NINDS tPA Stroke Trial, ${ }^{7}$ and the GAIN study ${ }^{11}$ have examined subsequent neurological deterioration following early improvement and shown that patients who improve are at the highest risk of deterioration. In the TOAST trial they found that patients with substantial acute recovery, defined as an improvement of greater or equal to $75 \%$ on NIHSS between baseline and 24 hours, were more likely to suffer a neurological deterioration in the following three months. Analysis of the GAIN study confirmed that very early recovery put patients at the highest risk of neurological deterioration. ${ }^{11}$ Multiple pathophysiological processes can explain this association. Rapid recovery may indicate reversal of ischemia but the underlying mechanism of the stroke event remains active or unstable leading to the higher recurrence risk. ${ }^{2,7}$

In the current study, we found that increasing HSSS was associated with a greater likelihood of identifying an intracranial arterial occlusion. Hemodynamic compromise due to intracranial occlusion is a plausible mechanism for deterioration in these patients. ${ }^{12}$ In centres where access to acute vascular imaging is difficult, the HSS may be useful in triaging patients to early vascular imaging, aggressive treatments and hospital admission all with a goal of preventing symptom progression.
We found that our motor, but not our speech score was associated with progression. This may reflect some difficulties with assessing how severe aphasia was by history. Quantifying motor power is likely easier than aphasia based on history as a patient is either unable to move the limb, is mildly affected or somewhere in between. We emphasize that our score relies on English language interpretation of the nuances of patient descriptors of their symptoms. Words such as "numbness" or "heaviness" may imply motor weakness in English but literal translations in other languages may not. Assessment of language based on history is more difficult as many of the components of aphasia such as reading and writing would not be assessed by this approach. Further it is often quite challenging in the acute assessment, to convincingly distinguish between dysarthria and expressive aphasia or verbal apraxia. Difficulty in measurement may have prevented the quantification of speech impairment as an important historical symptom.

Limitations of this study include the single centre nature of this observational study and our conclusions would be bolstered by validation in an independent population with simultaneous reliability testing. Another limitation is that we chose to only include motor and speech assessment rather than other neurological symptoms. We made this decision a priori as motor or speech symptoms were required for study enrolment in the main CATCH study. This means that these results are only relevant to a high risk TIA and minor stroke population. Further work assessing other aspects of neurological symptoms may be important. Another limitation is that the score is based on the patient's recollection and therefore subject to recall bias.

In conclusion, a score based on the historical description of how severe the worst motor deficits were can predict symptom progression, intracranial vessel occlusion and functional outcome in a TIA and minor stroke population. Amidst our increased reliance on technology and cerebral imaging, a good clinical history still plays an important role in helping to determine which patients are at the greatest risk of symptom progression following a TIA or a minor stroke.

\section{Funding Sources}

Canadian Institute of Health Research (CIHR) and a Pfizer Cardiovascular research award.

\section{ACKNOWLEDGEMENTS}

The authors thank the members of the Calgary Stroke Program for their help in conducting this study. Dr Hill receives salary support from Alberta Innovates-Health Solutions and the Heart \& Stroke Foundation of Alberta/NWT/NU. Dr Coutts receives salary support from the Alberta-Innovates-Health solutions and the Heart and Stroke Foundation of Canada's Distinguished Clinician Scientist award, supported in partnership with the Canadian Institute of Health Research (CIHR), Institute of Circulatory and Respiratory Health and AstraZeneca Canada Inc. 


\section{REFERENCES}

1. Johnston SC, Gress DR, Browner WS, Sidney S. Short-term prognosis after emergency department diagnosis of TIA. JAMA. 2000;284:2901-6.

2. Rothwell PM, Giles MF, Flossmann E, et al. A simple score $(A B C D)$ to identify individuals at high early risk of stroke after transient ischaemic attack. Lancet. 2005;366:29-36.

3. Johnston SC, Rothwell PM, Nguyen-Huynh MN, et al. Validation and refinement of scores to predict very early stroke risk after transient ischaemic attack. Lancet. 2007;369:283-92.

4. Selvarajah JR, Smith CJ, Hulme S, et al. Prognosis in patients with transient ischaemic attack (TIA) and minor stroke attending TIA services in the north west of England: The northstar study. J Neurol Neurosurg Psychiatry. 2008;79:38-43.

5. Coutts SB, Kelloway L. Chapter 2: Prevention of stroke. Canadian Best Practice Recommendations for Stroke Care. 2012.

6. Johnston SC, Leira EC, Hansen MD, Adams HP, Jr. Early recovery after cerebral ischemia risk of subsequent neurological deterioration. Ann Neurol. 2003;54:439-4.

7. Johnston SC, Easton JD. Are patients with acutely recovered cerebral ischemia more unstable? Stroke. 2003;34:2446-50.
8. Coutts SB, Hill MD, Campos CR, et al. Recurrent events in transient ischemic attack and minor stroke: What events are happening and to which patients? Stroke. 2008;39:2461-6.

9. Asdaghi N, Hameed B, Saini M, Jeerakathil T, Emery D, Butcher $\mathrm{K}$. Acute perfusion and diffusion abnormalities predict early new MRI lesions 1 week after minor stroke and transient ischemic attack. Stroke. 2011;42:2191-5.

10. Coutts SB, Modi J, Patel SK, Demchuk AM, Goyal M, Hill MD. $\mathrm{CT} / \mathrm{CT}$ angiography and MRI findings predict recurrent stroke after transient ischemic attack and minor stroke: Results of the prospective catch study. Stroke. 2012;43:1013-17.

11. Aslanyan S, Weir CJ, Johnston CS, Krams M, Grieve AP, Lees KR. The association of post-stroke neurological improvement with risk of subsequent deterioration due to stroke events. Eur J Neurol. 2007;14:1-6.

12. Alexandrov AV, Felberg RA, Demchuk AM, et al. Deterioration following spontaneous improvement: sonographic findings in patients with acutely resolving symptoms of cerebral ischemia. Stroke. 2000;31:915-19. 